\title{
A revised approach to the foF2 long-term trends analysis
}

\author{
A. V. Mikhailov ${ }^{1}$, D. Marin ${ }^{2}$, T. Yu. Leschinskaya ${ }^{1}$, and M. Herraiz ${ }^{3}$ \\ ${ }^{1}$ Institute of Terrestrial Magnetism, Ionosphere and Radio Wave Propagation, Troitsk, Moscow Region 142190, Russia \\ ${ }^{2}$ Atmospheric Sounding Station "El Arenosillo", INTA, Spain \\ ${ }^{3}$ Faculty of Physics, Complutense University, Spain
}

Received: 14 March 2001 - Revised: 4 February 2002 - Accepted: 6 February 2002

\begin{abstract}
A new approach to extract $f o \mathrm{~F} 2$ long-term trends, which are free to a great extent from solar and geomagnetic activity effects, has been proposed. These trends are insensitive to the phase (increasing/decreasing) of geomagnetic activity, with long-term variations being small and insignificant for such relatively short time periods. A small but significant residual $f o \mathrm{~F} 2$ trend, with the slope $K_{r}=-2.2 \times 10^{-4}$ per year, was obtained over a 55-year period (the longest available) of observations at Slough. Such small trends have no practical importance. On the other hand, negative (although insignificant) residual trends obtained at 10 ionosonde stations for shorter periods (31 years) may be considered as a manifestation of a very long-term geomagnetic activity increase which did take place during the 20th century. All of the revealed $f o \mathrm{~F} 2$ long-term variations (trends) are shown to have a natural origin related to long-term variations in solar and geomagnetic activity. There is no indication of any manmade $f o \mathrm{~F} 2$ trends.
\end{abstract}

Key words. Ionosphere (ionosphere-atmosphere interactions, ionospheric disturbances)

\section{Introduction}

Due to an increasing interest in the anthropogenic impact on the Earth's atmosphere the ionospheric parameter longterm trends are widely discussed in recent publications (Bremer, 1992, 1998; Givishvili and Leshchenko, 1994, 1995; Givishvili et al., 1995; Danilov, 1997, 1998; Ulich and Turunen, 1997; Rishbeth, 1997; Jarvis et al., 1998; Upadhyay and Mahajan, 1998; Sharma et al., 1999; Foppiano et al., 1999; Danilov and Mikhailov, 1999; Mikhailov and Marin, 2000; Deminov et al., 2000; Danilov and Mikhailov, 2001). The interest in the ionospheric trend analysis was greatly stimulated by the model calculations of Rishbeth (1990) and Rishbeth and Roble (1992), who predicted the ionospheric effects of the atmosphere greenhouse gas concentration in-

Correspondence to: A. V. Mikhailov (avm71@orc.ru) crease. Since then, researchers have been trying to reveal the predicted ionospheric effects related to the thermosphere cooling (Bremer, 1992; Givishvili and Leshchenko, 1994; Ulich and Turunen, 1997, Jarvis et al., 1998; Upadhyay and Mahajan, 1998). The atmosphere cooling effect should have been noticeable in the $h m \mathrm{~F} 2$ rather than in the $f o \mathrm{~F} 2$ trends, due to a weak dependence of $N m \mathrm{~F} 2$ on neutral temperature. Moreover, the expected neutral temperature decrease due to the greenhouse effect should result in a positive $f o \mathrm{~F} 2$ trend in contrast to the observations (Mikhailov and Marin, 2000). The analyzes have shown that there are well-pronounced and significant $h m \mathrm{~F} 2$ as well as $f o \mathrm{~F} 2$ trends. The worldwide pattern of the F2-layer parameter trends turned out to be very complicated and this cannot be reconciled with the greenhouse hypothesis. On the other hand, one cannot exclude the anthropogenic effects in the upper atmosphere related to the increasing rate of rocket and satellite launching during the last few decades, which has led to the thermosphere pollution (Kozlov and Smirnova, 1999; Adushkin et al., 2000). Therefore, further efforts are required in this direction to find out the physical mechanism of the F2-layer trends.

Despite many publications devoted to the F2-layer parameter long-term trends, the results of different authors are still contradictory to a great extent. This is due to both the accuracy of the experimental material and the methods used to extract long-term trends from the observations. The most suitable for the trend analysis parameter is the F2-layer critical frequency. It has been observed routinely over the worldwide ionosonde network for 3-5 solar cycles using one and the same method of ionospheric sounding. The critical frequency, $f o \mathrm{~F} 2$, is registered directly (unlike $h m \mathrm{~F} 2$ ) and with an acceptable accuracy of $\approx 0.1 \mathrm{MHz}$. Unlike $f o \mathrm{E}$ or $f o \mathrm{~F} 1$, the F2-layer critical frequency is observed all day long and this allows one to follow diurnal variations in the $f o \mathrm{~F} 2$ longterm trends. But even in case of $f o \mathrm{~F} 2$, the useful "signal" is very small and the "background" is very noisy, therefore, the success of analysis depends strongly on the method used. An approach being developed by Danilov and Mikhailov (1999) and Mikhailov and Marin $(2000,2001)$ has allowed us to 


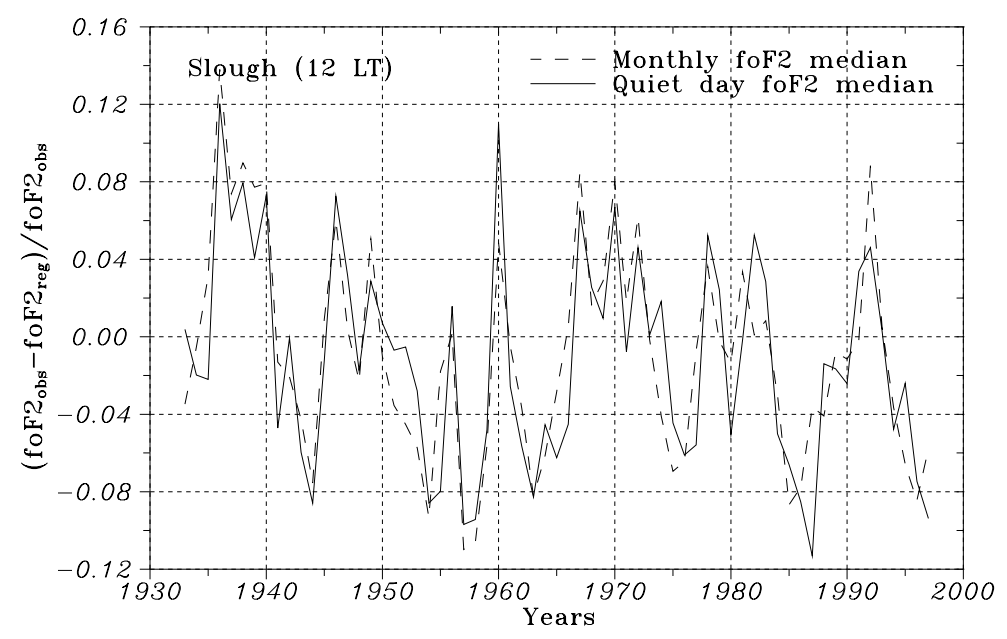

Fig. 1. A comparison of annual mean $\delta f o \mathrm{~F} 2$ variations at Slough $(12: 00 \mathrm{LT})$ when the usual monthly median and $Q$ median $f o F 2$ values are used in the calculations. find systematic variations in $f o \mathrm{~F} 2$ and $h m \mathrm{~F} 2$ trends, unlike other approaches (e.g. Bremer, 1998; Upadhyay and Mahajan, 1998), resulting in various signs and magnitudes of the trends at various stations. An application of this approach to the $f o \mathrm{~F} 2$ trend analysis resulted in a geomagnetic control concept (Mikhailov and Marin, 2000, 2001) to explain the revealed latitudinal and diurnal variations of the F2-layer parameter long-term trends. It was shown that an interpretation of the F2-layer parameter trends should consider the geomagnetic effects as an inalienable part of the trends revealed and this can be done based on the contemporary understanding of the F2-layer storm mechanisms (Mikhailov and Marin, 2000, 2001).

Although the geomagnetic control concept allowed us to explain the main morphological features of the $f_{o} \mathrm{~F} 2$ longterm trends revealed, there are still some questions remaining. The most important one is whether it is possible to remove the geomagnetic effect from the $f o \mathrm{~F} 2$ long-term variations, in order to analyze the residual trends. What is the origin (anthropogenic or natural) of such residual trends if they exist? Earlier developed approaches cannot be used for such analysis as they give $f o \mathrm{~F} 2$ trends that are strongly contaminated with geomagnetic activity effects, despite the attempts to delete them (Mikhailov and Marin, 2000, 2001). Therefore, a revised method has been developed in this paper which allows us to delete to a great extent solar and geomagnetic activity effects from the observed foF2 long-term variations and reveal the residual $f_{o} \mathrm{~F} 2$ trends.

\section{Method description}

A revised method described here is based on the analysis given in Sect. 3 of the paper. The final version of the method comprises the following.

1. We proceed from an assumption that observed $f_{o} \mathrm{~F} 2$ variations are mainly due to solar and long-term geomagnetic activity variations that (with some reservations) may be described with $R_{12}$ and 11-year running mean $A p$ indices. The results of our analysis (see later) have shown that such a combination provides the best description accuracy and the most consistent results. Therefore, the method includes the following steps. A regression of monthly foF 2 with $R_{12}$

$f o F 2_{\text {reg }}=a_{0}+a_{1} R_{12}^{\alpha}$

is used to find monthly relative deviations

$\delta f_{o} F 2=\left(f o F 2_{o b s}-f o F 2_{r e g}\right) / f o F 2_{o b s}$.

We analyze (for each LT moment) relative rather than absolute $\delta f o \mathrm{~F} 2$ deviations considered in the $f o \mathrm{~F} 2$ and $h m \mathrm{~F} 2$ trend analyzes by Bremer (1998); Ulich and Turunen (1997); Jarvis et al. (1998); Upadhyay and Mahajan (1998); Sharma et al. (1999); Foppiano et al. (1999). As far as we know relative deviations were considered only by Deminov et al. (2000) in their foF2 long-term trend analysis. Relative deviations allow us to combine different months and obtain an annual mean $\delta f o \mathrm{~F} 2$ that is used in the analysis, with the final method being based on the 11-year running mean $\delta f o \mathrm{~F} 2$ values. A simple arithmetic running mean smoothing with an 11-year gate is applied everywhere.

The optimal 12 different values of $\alpha$ (for each month of the year) are specified to provide the least standard deviation $(S D)$ after a regression (see later) of an 11-year smoothed $\delta f o \mathrm{~F} 2$ with $A p_{132}$ (11-year running mean $\mathrm{Ap}$ indices). The 11-year $\delta f o \mathrm{~F} 2$ smoothing requires all 12 values of $\alpha$ to be available simultaneously at each step of the $S D$ minimization. This implies an application of special multi-regressional methods (Press et al., 1992) matched to solve the problem considered.

The expression (1) is of a general type and depending on $\alpha$, it can describe both the linear and nonlinear relationship of $f_{0} \mathrm{~F} 2$ with $R_{12}$. The regression coefficients $a_{i}$ are specified by the least-squares method for each 

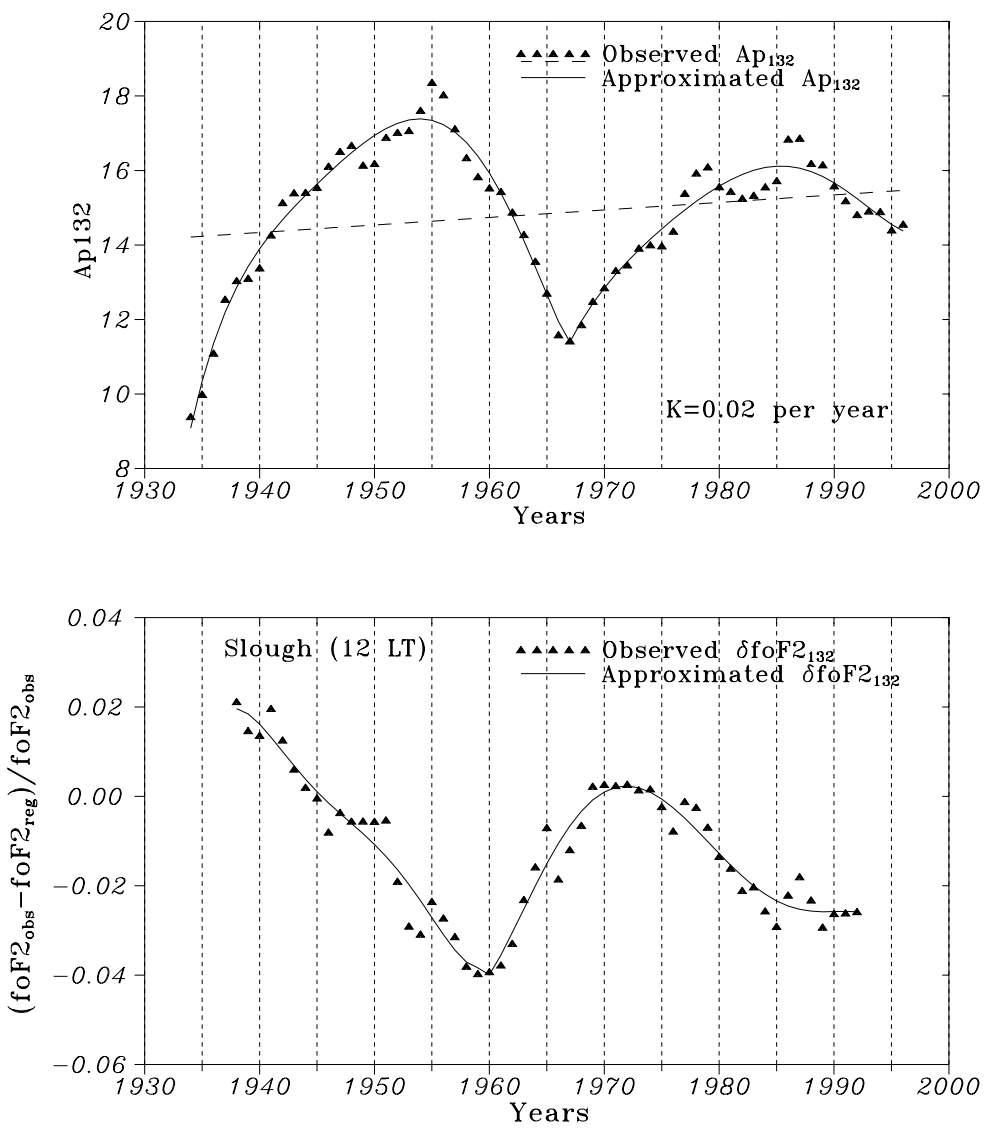

Fig. 2. Observed and polynomial approximated $A p_{132}$ and $\delta f o \mathrm{~F} 2132$ variations used in the trend analysis. Dashed line is a linear, very long-term trend with the slope $\mathrm{K}=0.02$ per year in geomagnetic activity obtained over the observed $A p_{132}$ variations. Note also a 4-year shift between the $A p_{132}$ and $\delta f o \mathrm{~F} 2132$ variations. month and a given $\alpha$ value. It should be stressed that the expression (1) does not provide the best approximation of the observed $f o \mathrm{~F} 2$ versus $R_{12}$ dependence (other dependencies may yield a smaller sum of the residuals), but it should be considered in terms of the following regression with $A p_{132}$ to find the minimal $S D$ (see later). Therefore, the regression (1) is not a "model" in the usual sense of the word, since it is accepted in all earlier approaches. This regression is used to remove the solar activity part from the observed $f o \mathrm{~F} 2$ variations as a "pure" $f o \mathrm{~F} 2$ dependence on solar activity (presented by the $R_{12}$ index) a priori is not known for each month (see Sect. 6: Discussion).

2. $Q$-medians proposed by Deminov et al. (2000) are used in the method instead of the usual monthly foF2 ones. Such $Q$-medians are obtained over quiet days of each month. In our approach, unlike that of Deminov et al. (2000), a day is considered to be quiet if daily $A p \leq 10$ for this and the two previous days. The $Q$-median value is set to zero if there are no such days in a month. A threshold was set to 1 and 3 quiet days a month. Testing has shown that generally 3-quiet day medians provide better results for some stations, but too many gaps in the observations, due to such severe selection, led to peculiar results on other stations. Therefore, the 1-quiet day threshold has been accepted. An example of annual mean $\delta f o \mathrm{~F} 2$ (after Eq. 2) variations obtained with the usual monthly and $Q$-medians is shown in Fig. 1. The difference is seen for the two cases, both during the periods of solar maximum and minimum. It may seem not to be very large, but one should keep in mind that during the trend analysis, we work at the level of noise and even small differences in the initial material may affect the final result. Despite the removal of short-term (monthly) geomagnetic effects by using $Q$-medians, strong yearto-year $\delta f o F 2$ fluctuations take place (Fig. 1). These oscillations may be related to the variations in solar activity (Ivanov-Kholodny and Chertoprud, 1992; IvanovKholodny, 2000), but they are not removed by any regression with $R_{12}$ or $A p$, and an 11-year running mean smoothing is applied to conquer them (see later).

3. Unlike our earlier method, where only years around solar cycle maxima and minima were analyzed to avoid the hysteresis effect at the rising and falling parts of solar cycles, the proposed method uses all years available. A comparison has shown close results for different year selections using the proposed method. This takes away the problem of using different year selections for $f o \mathrm{~F} 2$ and $h m \mathrm{~F} 2$ trend analysis (Marin et al., 2001; Mikhailov and Marin, 2001).

Gaps in observations are not filled in. If the number 
Table 1. Correlation coefficients, $r$, between $\delta f o F 2132$ and $A p_{132}$ found over one and the same period $1957-97$ (1962-92 after 11-year smoothing). The "appr." refers to the polynomial approximated $\delta f o \mathrm{~F} 2132$ and $A p_{132}$ variations. The first line refers to $Q$-medians, the second to the usual monthly $f o \mathrm{~F} 2$ medians used in the calculations. Bold face figures show significant $r$ with a confidence level $99 \%$, normal face figures correspond to $95 \%$ confidence level, italic figures are not significant $r$. The optimal time shift $\Delta t$ (in years) between $\delta f o \mathrm{~F} 2{ }_{132}$ and $A p_{132}$ variations is given as well

\begin{tabular}{|c|c|c|c|c|c|c|c|c|}
\hline \multirow[b]{2}{*}{ Station } & \multicolumn{4}{|c|}{ 00:00 LT } & \multicolumn{4}{|c|}{ 12:00 LT } \\
\hline & $\begin{array}{c}\delta f o \mathrm{~F} 22_{132} \text { appr. } \\
\text { vs. } A p_{132}\end{array}$ & $\Delta t$ & $\begin{array}{l}\delta f o \mathrm{~F} 2132 \text { app } 1 \\
\text { vs. } A p_{132} \text { app }\end{array}$ & $\overline{\Delta t}$ & $\begin{array}{c}\delta f_{o} \mathrm{~F} 2_{132} \text { appr. } \\
\text { vs. } A p_{132}\end{array}$ & $\Delta t$ & $\begin{array}{l}\delta f o \mathrm{~F} 2132 \text { appr. } \\
\text { vs. } A p_{132} \text { appr. }\end{array}$ & $\overline{\Delta t}$ \\
\hline \multirow[t]{2}{*}{ Lycksele } & -0.773 & 0 & -0.778 & 0 & -0.906 & -2 & -0.932 & -2 \\
\hline & -0.863 & -5 & -0.859 & -5 & -0.959 & 0 & -0.984 & 0 \\
\hline \multirow[t]{2}{*}{ Uppsala } & -0.911 & -2 & -0.943 & -2 & -0.919 & -2 & -0.946 & -2 \\
\hline & -0.758 & -2 & -0.757 & -2 & -0.938 & 0 & -0.977 & 0 \\
\hline \multirow[t]{2}{*}{ St. Petersburg } & -0.504 & -2 & -0.493 & -2 & -0.927 & -3 & -0.957 & -3 \\
\hline & -0.734 & 0 & -0.771 & 0 & -0.887 & -1 & -0.913 & -1 \\
\hline \multirow[t]{2}{*}{ Juliusruh } & -0.843 & -2 & -0.857 & -2 & -0.881 & -3 & -0.898 & -3 \\
\hline & -0.881 & 0 & -0.916 & 0 & -0.882 & -2 & -0.908 & -2 \\
\hline \multirow[t]{2}{*}{ Moscow } & -0.828 & -2 & -0.842 & -2 & -0.928 & -3 & -0.974 & -3 \\
\hline & -0.922 & 0 & -0.948 & 0 & -0.908 & -2 & -0.942 & -2 \\
\hline \multirow[t]{2}{*}{ Tomsk } & -0.684 & -3 & -0.671 & -3 & -0.629 & -3 & -0.608 & -3 \\
\hline & -0.795 & 0 & -0.828 & 0 & -0.809 & 0 & -0.833 & 0 \\
\hline \multirow[t]{2}{*}{ Slough } & -0.902 & -3 & -0.921 & -2 & -0.941 & -3 & -0.971 & -3 \\
\hline & -0.791 & 0 & -0.817 & 0 & -0.935 & -2 & -0.977 & -2 \\
\hline \multirow[t]{2}{*}{ Dourbes } & -0.918 & -4 & -0.960 & -4 & -0.861 & -4 & -0.918 & -4 \\
\hline & -0.845 & -1 & -0.856 & -1 & -0.725 & -2 & -0.756 & -3 \\
\hline \multirow[t]{2}{*}{ Poitiers } & -0.916 & -4 & -0.931 & -4 & -0.859 & -4 & -0.894 & -4 \\
\hline & -0.924 & -2 & -0.957 & -2 & -0.770 & -5 & -0.817 & -4 \\
\hline \multirow[t]{2}{*}{ Rome } & -0.933 & -2 & -0.967 & -2 & +0.919 & -3 & +0.951 & -3 \\
\hline & -0.853 & -4 & -0.865 & -4 & -0.594 & -3 & -0.625 & -3 \\
\hline
\end{tabular}

of months with available $f_{o} \mathrm{~F} 2$ values for a given year is less than 6, then the year is marked as "zero". During the 11-year $\delta f o \mathrm{~F} 2$ smoothing, the arithmetic mean is calculated over the non-zero years only.

4. The geomagnetic activity effect is deleted from the 11year running mean $\delta f_{o} \mathrm{~F} 2$ variation using a regression with $A p_{132}$

$$
\begin{aligned}
\delta f_{0} F 2_{132}=b_{0} & +b_{1} A p_{132}(t+n) \\
& +b_{2} A p_{132}^{2}(t+n),
\end{aligned}
$$

where $n$ is a time shift in years of $A p_{132}$ with respect to $\delta f o \mathrm{~F} 2132$ variations, which is selected to give the least $S D$ for the residuals after Eq. (3). The regression coefficients $b_{i}$ are specified by the least-squares method. A nonlinear dependence of $\delta f o \mathrm{~F} 2$ on the geomagnetic activity is expected in accordance with Zevakina and Kiseleva (1978) and Muhtarov and Kutiev (1998).

5. An analysis has shown that the best results (the least $S D$ ) can be obtained if an additional smoothing is applied to $\delta f o \mathrm{~F}_{2} 132$ and $A p_{132}$ variations. Such smoothing is made by a 5 -order polynomial approximation of these parameter variations. The initial and approximated $A p_{132}$ and $\delta f o \mathrm{~F} 2_{132}$ variations are shown in Fig. 2 for Slough (12:00 LT) as an example. A 4-year shift is clearly seen between the two variations.
6. The residual linear trend with the slope $K_{r}$ (in $10^{-4}$ per year) is estimated over the residuals after the regression (3).

7. The test of significance for the linear trend parameter $K_{r}$ (the slope), as well as for the correlation between the parameters analyzed, is made with Fisher's $F$ criterion (Pollard, 1977)

$F=r^{2}(N-2) /\left(1-r^{2}\right)$,

where $r$ is the correlation coefficient and $N$ is the number of pairs considered. Keeping in mind that we work with smoothed variations we set the number of degrees of freedom to be $(N-2)=4$ (the 5th order polynomial is defined by 6 coefficients). Such tough requirements on the $(N-2)$ value formally results in insignificant trends, in many cases, despite the existence of obvious and pronounced trends calculated over some dozens of points. Sometimes the number of degrees of freedom is higher than 4 and this is mentioned separately in each case. Student's T-criterion (Pollard,1977) was used to test whether the difference between values is significant.

\section{Choosing a combination of parameters}

In developing the method we have considered monthly, the annual mean and the 11-year running mean $\delta f o \mathrm{~F} 2$, to find the 
Table 2. Correlation coefficients, $r$, between $\delta f o \mathrm{~F} 2{ }_{132}$ and $R_{132}$ found over one and the same period 1957-97 (1962-92 after 11-year smoothing). The "appr." refers to the polynomial approximated $\delta f o \mathrm{~F} 2132$ and $R_{132}$ variations. The first line refers to $Q$-medians, the second to the usual monthly $f o \mathrm{~F} 2$ medians used in the calculations. Bold face figures show significant $r$ with a confidence level $99 \%$, normal face figures correspond to $95 \%$ confidence level, italic figures are not significant $r$. The optimal time shift $\Delta t$ (in years) between $\delta f o F 2132$ and $R_{132}$ variations is given as well

\begin{tabular}{|c|c|c|c|c|c|c|c|c|}
\hline \multirow[b]{2}{*}{ Station } & \multicolumn{4}{|c|}{$00: 00 \mathrm{LT}$} & \multicolumn{4}{|c|}{ 12:00 LT } \\
\hline & $\begin{array}{c}\delta f o \mathrm{~F} 2132 \text { appr. } \\
\text { vs. } R_{132}\end{array}$ & $\Delta t$ & $\begin{array}{l}\delta f o \mathrm{~F} 2_{132} \text { appr. } \\
\text { vs. } R_{132} \text { appr. }\end{array}$ & $\Delta t$ & $\begin{array}{c}\delta f o \mathrm{~F} 2132 \text { appr. } \\
\text { vs. } R_{132}\end{array}$ & $\Delta t$ & $\begin{array}{l}\delta f o \mathrm{~F} 2132 \text { appr. } \\
\text { vs. } R_{132} \text { appr. }\end{array}$ & $\Delta t$ \\
\hline \multirow[t]{2}{*}{ Lycksele } & -0.631 & 0 & -0.768 & 0 & -0.791 & -1 & -0.924 & -1 \\
\hline & -0.888 & -5 & -0.885 & -4 & -0.845 & 0 & -0.921 & 0 \\
\hline \multirow[t]{2}{*}{ Uppsala } & -0.849 & -1 & -0.952 & -1 & -0.891 & 0 & -0.947 & -1 \\
\hline & -0.548 & -3 & -0.728 & -2 & -0.789 & 0 & -0.910 & 0 \\
\hline \multirow[t]{2}{*}{ St. Petersburg } & -0.400 & -5 & -0.425 & -4 & -0.905 & -3 & -0.973 & -3 \\
\hline & -0.450 & 0 & -0.575 & 0 & -0.720 & 0 & -0.852 & -1 \\
\hline \multirow[t]{2}{*}{ Juliusruh } & -0.683 & -1 & -0.849 & -1 & -0.795 & -3 & -0.911 & -2 \\
\hline & -0.699 & 0 & -0.843 & 0 & -0.775 & -2 & -0.887 & -2 \\
\hline \multirow[t]{2}{*}{ Moscow } & -0.718 & -3 & -0.851 & -2 & -0.948 & -2 & -0.994 & -2 \\
\hline & -0.774 & 0 & -0.890 & 0 & -0.843 & -1 & -0.924 & -2 \\
\hline \multirow[t]{2}{*}{ Tomsk } & -0.608 & -5 & -0.659 & -3 & -0.596 & -5 & -0.614 & -4 \\
\hline & -0.545 & 0 & -0.674 & 0 & -0.613 & 0 & -0.682 & 0 \\
\hline \multirow{2}{*}{ Slough } & -0.768 & -2 & -0.919 & -2 & -0.942 & -4 & -0.996 & -3 \\
\hline & -0.555 & 0 & -0.672 & 0 & -0.949 & -2 & -0.991 & -1 \\
\hline \multirow[t]{2}{*}{ Dourbes } & -0.939 & -4 & -0.997 & -4 & -0.896 & -3 & -0.960 & -4 \\
\hline & -0.737 & -1 & -0.762 & -1 & -0.662 & -2 & -0.730 & -3 \\
\hline \multirow[t]{2}{*}{ Poitiers } & -0.922 & -5 & -0.957 & -3 & -0.852 & -4 & -0.947 & -5 \\
\hline & -0.837 & -1 & -0.951 & -1 & -0.767 & -2 & -0.830 & -4 \\
\hline \multirow[t]{2}{*}{ Rome } & -0.867 & -1 & -0.981 & -1 & +0.869 & -1 & +0.957 & -2 \\
\hline & -0.869 & -5 & -0.898 & -4 & -0.509 & -1 & -0.558 & -3 \\
\hline
\end{tabular}

combination which would provide the least $S D$ after deleting the geomagnetic activity effect. The latter was supposed to be presented by smoothed or non-smoothed $A p$ or $R_{12}$ indices. Usual monthly and $Q$-median, smoothed and nonsmoothed foF 2 values were considered. The $R_{12}$ index was considered (along with $A p$ ) as an indicator of long-term solar/geomagnetic activity variations (Deminov et al., 2000). In the beginning we examined the correlation coefficients between $\delta f_{o} \mathrm{~F} 2$ and $A p$ (or $R_{12}$ ) indices. Only the results which led us to the final method (Sect. 2) are presented here.

All correlation coefficients for monthly, as well as for annual mean $\delta f o \mathrm{~F} 2$, are found to be low (0.2-0.5), both for nonsmoothed and smoothed Ap (or $R_{12}$ ) indices and, therefore, cannot be considered as candidates for the method. An essential increase in the correlation coefficient takes place only after moving to 11-year running mean values. An additional increase in the correlation is possible if one applies a smoothing approximation to $\delta f o \mathrm{~F}_{132}$ and $A p_{132}$ (or $R_{132}$ ) variations (Fig. 2). Such approximated values provide the largest correlation coefficients and the least $S D$; therefore, this approach was used in the final method.

The testing results over 10 stations are given in Tables 1 and 2, where $Q$ - and the usual monthly foF 2 medians are compared. $A p_{132}$ and $A p_{132}$ approximated indices were used in Table 1, while $R_{132}$ and $R_{132}$ approximated - in Table 2. One and the same period 1957-1997 (1962-1992 after the 11-year smoothing) for all stations was considered. Max- imal correlation coefficients corresponding to the optimal time shift of $A p_{132}$ (or $R_{132}$ ), with respect to $\delta f o \mathrm{~F} 2{ }_{132}$ variations, are given in Tables 1 and 2 for 00:00 and 12:00 LT.

The results of Tables 1 and 2 show that the correlation coefficients are larger when both approximated $\delta f o \mathrm{~F} 2132$ and $A p_{132}$ (or $R_{132}$ ) variations are considered. The difference when approximated and non-approximated indices are used is significant at the $99.9 \%$ confidence level according to the T-criterion. The use of $Q$-medians compared to the usual monthly ones provides a larger number of significant cases. The percentage of significant cases ( $Q$-medians/usual medians) is $80 \% / 67 \%$ when $A p_{132}$ is used, and $67 \% / 45 \%$ when $R_{132}$ is considered. Therefore, $Q$-medians seem to be preferable for the method. On the other hand, the difference between significant correlation coefficients from Tables 1 and 2 is not significant according to the T-criterion when $A p_{132}$ is used, and the difference between the two medians is significant at the $98 \%$ confidence level ( $Q$-medians are better) when $R_{132}$ is considered. Thus, some additional characteristics should be compared. A comparison of the time shift between $\delta f o \mathrm{~F} 2$ and $A p_{132}$ (or $R_{132}$ ) variations can help select the best combination. The average optimal time shifts along with $S D$ calculated for the significant cases from Tables 1 and 2 are given in Table 3 . The $Q$-medians/A $p_{132}$ approximated combination provides the least $S D$ for the time shift, which is around -3 years. This combination has been chosen for the final method. 
Table 3. Average optimal time shift with $\pm S D$ between $\delta f o \mathrm{~F} 2$ and $A p_{132}$ (or $R_{132}$ ) approximated variations calculated from the results of Tables 1 and 2

\begin{tabular}{cc|cc}
\hline \multicolumn{2}{c|}{$Q$-medians } & \multicolumn{2}{c}{ Usual monthly medians } \\
\hline$A p_{132}$ appr. & $R_{132}$ appr. & $A p_{132}$ appr. & $R_{132}$ appr. \\
\hline$-2.8 \pm 0.83$ & $-2.3 \pm 1.25$ & $-1.4 \pm 1.59$ & $-1.6 \pm 1.62$ \\
\hline
\end{tabular}

Table 4. Ionosonde stations and calculated slope $K_{r}$ (in $10^{-4}$ per year) for the period of increasing geomagnetic activity $1965-1991 . K_{M+m}$ values from Mikhailov and Marin (2000) are given for a comparison. Bold face figures for $K_{M+m}$ show significant trends with a confidence level $\geq 90 \%$, italic face figures are trends which are not significant at the $90 \%$ confidence level

\begin{tabular}{l|c|c|cc|c|c|c|c}
\hline Station & $\Phi$ & $\Phi_{i n v}$ & \multicolumn{2}{|c|}{ Geographic } & \multicolumn{2}{c|}{$00: 00$ LT } & \multicolumn{2}{c}{$12: 00$ LT } \\
& Deg & Deg & Lat & \multicolumn{1}{c|}{ Lon } & \multicolumn{1}{c|}{$K_{r}$} & \multicolumn{1}{c}{$K_{M+m}$} & \multicolumn{1}{c}{$K_{r}$} & $K_{M+m}$ \\
\hline Lycksele & 62.70 & 61.42 & 64.70 & 18.80 & -6.21 & $+\mathbf{1 . 9}$ & -0.96 & $-\mathbf{2 6 . 0}$ \\
Uppsala & 58.44 & 56.61 & 59.80 & 17.60 & -0.56 & $-\mathbf{4 2 . 2}$ & -0.40 & $\mathbf{- 2 7 . 6}$ \\
St. Petersburg & 56.17 & 55.91 & 60.00 & 30.70 & -1.04 & -19.2 & -0.09 & $\mathbf{- 1 6 . 1}$ \\
Juliusruh & 54.40 & 51.61 & 54.60 & 13.40 & -1.80 & $-\mathbf{3 3 . 7}$ & -0.82 & $\mathbf{- 1 2 . 2}$ \\
Ekateringburg & 48.42 & 51.45 & 56.70 & 61.10 & -5.20 & $-\mathbf{3 0 . 2}$ & -0.31 & $\mathbf{- 1 2 . 0}$ \\
Moscow & 50.82 & 51.06 & 55.50 & 37.30 & -1.10 & $-\mathbf{2 5 . 6}$ & +0.31 & -12.0 \\
Tomsk & 45.92 & 50.58 & 56.50 & 84.90 & -0.95 & -16.9 & -1.10 & $+\mathbf{5 . 0}$ \\
Slough & 54.25 & 49.80 & 51.50 & 359.43 & -0.27 & -13.1 & -0.52 & -5.9 \\
Dourbes & 51.89 & 47.80 & 50.10 & 4.60 & -0.30 & $-\mathbf{3 . 9}$ & -0.25 & +1.7 \\
Poitiers & 49.40 & 45.05 & 46.60 & 0.30 & -0.83 & -9.4 & -0.67 & $-\mathbf{0 . 3}$ \\
Rome & 42.46 & 37.48 & 41.90 & 12.52 & 0.00 & $\mathbf{- 2 . 3}$ & -2.57 & $+\mathbf{6 . 2}$ \\
Ashkhabad & 30.39 & 30.55 & 37.90 & 58.30 & -0.40 & $\mathbf{- 4 . 4}$ & -0.88 & $\mathbf{- 1 . 4}$ \\
\hline
\end{tabular}

Table 5. Same as Table 4, but for the period of decreasing geomagnetic activity 1955-1970

\begin{tabular}{l|c|c|c|c}
\hline Station & \multicolumn{2}{|c|}{$00: 00 \mathrm{LT}$} & \multicolumn{2}{c}{$12: 00 \mathrm{LT}$} \\
& $K_{r}$ & $K_{M+m}$ & $K_{r}$ & $K_{M+m}$ \\
\hline Slough & +0.66 & $\mathbf{+ 3 8 . 9}$ & -1.29 & $\mathbf{+ 2 0 . 3}$ \\
Moscow & +0.25 & $\mathbf{+ 3 2 . 2}$ & -0.03 & $+\mathbf{1 6 . 2}$ \\
Tomsk & +0.46 & +12.4 & +0.06 & +15.2 \\
\hline
\end{tabular}

The obtained significant correlation coefficients (Tables 1 and 2) are seen to be large and negative both for 00:00 and 12:00 LT. The only case of positive correlation of $\delta f o \mathrm{~F} 2$ with geomagnetic activity is demonstrated at the lower latitude station of Rome at 12:00 LT, and this may be explained in the framework of contemporary F2-layer storm mechanisms (Mikhailov and Marin, 2001).

\section{Rising and falling periods in geomagnetic activity}

The basic points of the geomagnetic control concept by Mikhailov and Marin (2000) is the dependence of $f_{o} \mathrm{~F} 2$ trends on geomagnetic (invariant) latitude and the existence of negative/positive $f_{o} \mathrm{~F} 2$ trends for the periods of longterm increasing/decreasing geomagnetic activity. Both features were explained using the F2-layer storm mechanisms (Mikhailov and Marin, 2001). Therefore, if the revised approach is free of the geomagnetic control, then both features should be absent in the foF 2 trends revealed. The same period 1965-1991, as in Mikhailov and Marin (2000) of increasing geomagnetic activity (Fig. 2, top), was chosen for the analysis (Table 4). Keeping in mind the 11-year smoothing, only stations with available observations for the period 1960-1996 could be analyzed. Slopes $K$ for $(M+m)$ year selection from Mikhailov and Marin (2000) are given for a comparison. Table 4 shows that unlike our previous results the calculated trends do not demonstrate any latitudinal dependence being small and insignificant. Relatively large and insignificant $K_{r}$ for Lycksele (00:00 LT) and Rome (12:00 LT) are random and due to the scatter of data for the conditions in question.

Similar analysis was made for the $1955-1970$ period (Table 5) of decreasing geomagnetic activity (Fig. 2, top) for the 3 stations from Mikhailov and Marin (2000) where observations are available at least since 1950. The calculated trends are seen to be small and insignificant, while $K_{M+m}$ 

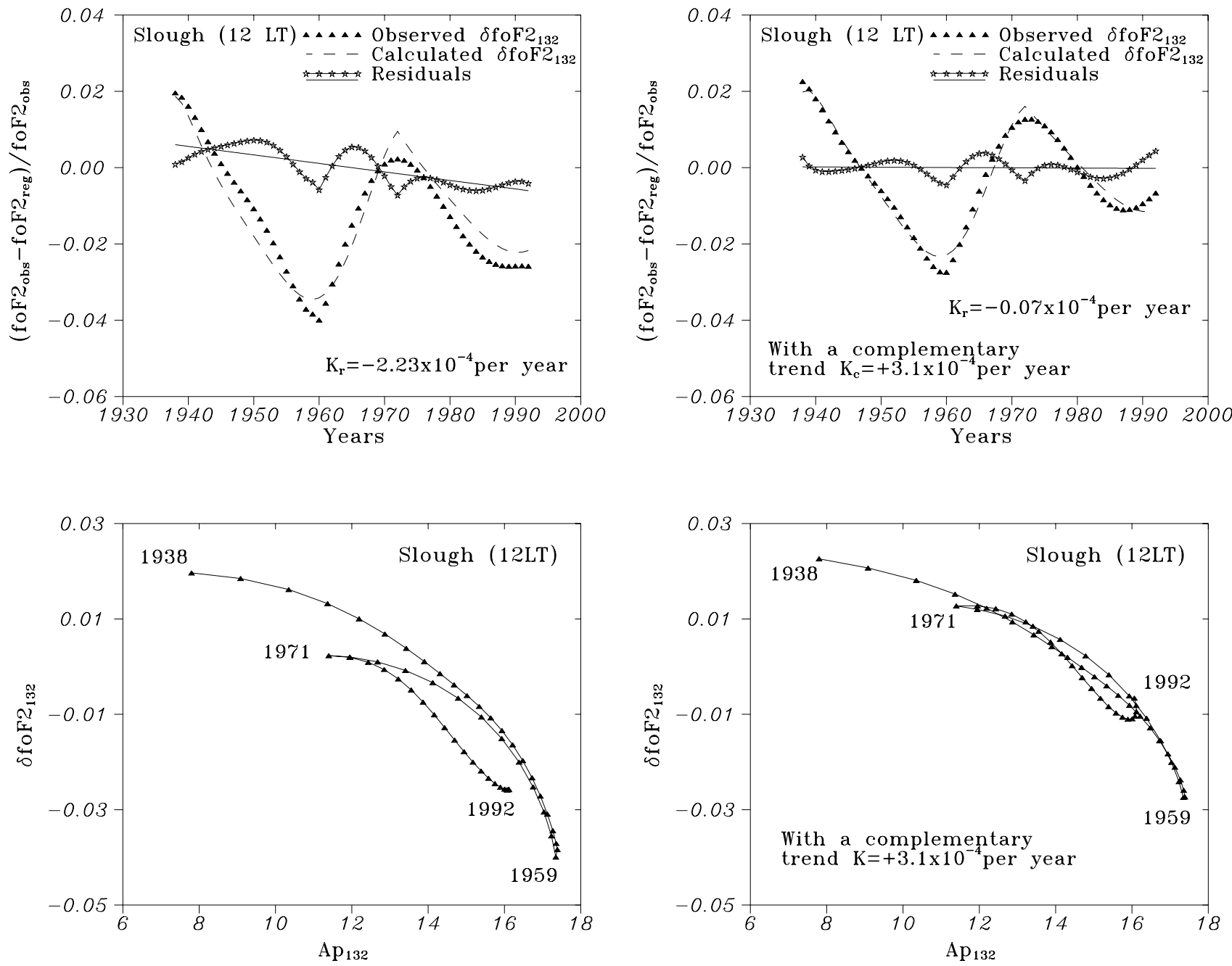

Fig. 3. Observed, calculated $\delta f o \mathrm{~F} 2132$ and their difference resulting in a residual $f o \mathrm{~F} 2$ trend with the slope $K_{r}$ for Slough 12:00 LT (top panels), along with the relationship between polynomial approximated $\delta f o \mathrm{~F} 2132$ and $A p_{132}$ (bottom panels). Right-hand panels show the results with a complementary trend $\left(K_{c}=+3.1 \times 10^{-4}\right.$ per year). Note the tightening of two branches in the $\delta f o F 2132$ versus $A p_{132}$ dependence (left-hand, bottom) after applying a complementary trend (right-hand, bottom).

are large and positive, in accordance with the geomagnetic control concept.

The results obtained show that the proposed method provides $f o \mathrm{~F} 2$ trends which are small, insignificant and latitudinal independent, regardless of the phase of the geomagnetic activity long-term variation. This means that trends are free of geomagnetic effects in terms of the geomagnetic control concept. On the other hand, most of the trends are seen to be negative (Table 4) and this may tell us about an additional mechanism affecting the trends (see later).

\section{Residual $f o F 2$ trends}

The obtained $f o \mathrm{~F} 2$ trends were shown to be insignificant for relatively short time intervals (rising or falling periods of geomagnetic activity). Obviously, high correlation coefficients, resulting in good fitting and small $K_{r}$, can be easier obtained for short time intervals, including only one branch of the geomagnetic activity variation, but this may not be the case for longer periods. Therefore, the method was applied to Slough where $f o \mathrm{~F} 2$ observations for 12:00 LT are available for the 1933-1997 period. After 11-year smoothing, the available period for analysis reduces to 1938-1992. Calculated and observed $\delta f o \mathrm{~F} 2132$ variations, as well as their differences, are shown in Fig. 3 (left-hand, top). The proposed method is seen to describe the main features of the observed $\delta f o \mathrm{~F} 2{ }_{132}$ variation. The residuals demonstrate a long-term linear trend with a slope $K_{r}=-2.23 \times 10^{-4}$ per year, which is significant at the $95 \%$ confidence level. Instead of pronounced negative foF 2 trends for the 1940-1960 and 1970-1992 periods and a positive trend for the 1960-1970 period, which we would have under the geomagnetic control concept, the residuals (Fig. 3) do not reflect these long-term variations in geomagnetic activity. Some fluctuations of the residuals around the regression line reflect the imperfection of the model fitting 

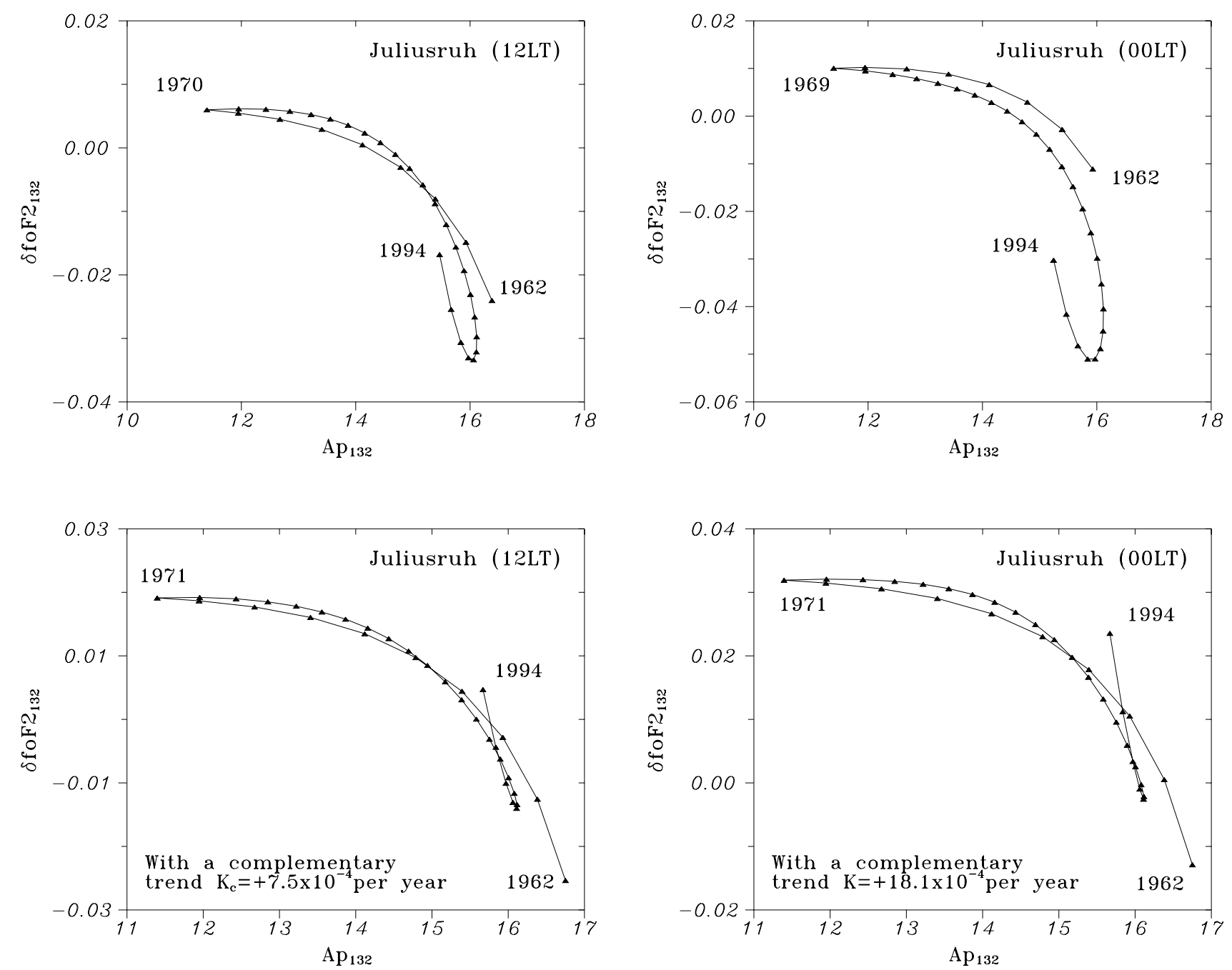

Fig. 4. Relationship between polynomial approximated $\delta f o \mathrm{~F} 2132$ and $A p_{132}$ for Juliusruh (12:00 and 00:00 LT) (top panels) and the same dependencies after applying a complementary trend (bottom). Note the tightening of the loops in the second case.

the observed $\delta f o \mathrm{~F} 2132$ variations.

Strong diurnal variation of the $f o \mathrm{~F} 2$ trend magnitude was another feature revealed and explained in the framework of the geomagnetic control concept (Mikhailov and Marin, $2000,2001)$. This was also checked for Slough where $f o F 2$ observations for all LT moments are available for the 19441997 period. The results of the calculations are given in Table 6. Unlike our previous results, the calculated $K_{r}$ are small and most of them are insignificant all day long. Only trends around noon and in the evening turn out to be significant. Despite this insignificance in the trends (which were calculated absolutely independently for 24 LT moments), they clearly demonstrate a consistent pattern of some diurnal variation (Table 6). This means that the calculated trends are not random and may need physical interpretation in future. The important result for further discussion is that most of the trends in Table 6 are negative similar to the conclusion made in Table 4. The optimal time shift between $A p_{132}$ and $\delta f o \mathrm{~F} 22_{132}$ variations averaged over $24 \mathrm{LT}$ moments is $-3.4 \pm 0.88$ years.
This is comparable with the estimate obtained over 10 stations for $12 \mathrm{LT}$ (Table 3 , the $Q$-medians/ $A p_{132}$ approximated combination).

The residual trend is seen to result from incomplete fitting of the calculated $\delta f o \mathrm{~F} 2_{132}$ variation to the observed one (Fig. 3, left-hand, top). This is due to the $\delta f o \mathrm{~F} 2{ }_{132}$ versus $A p_{132}$ regression used in the calculations. The left-hand bottom panel of Fig. 3 gives a dependence between approximated $\delta f o \mathrm{~F} 2_{132}$ and $A p_{132}$ values used in the calculations. Two branches are seen in this dependence: one - before the end of the 1950s, the other - after 1971. The type of dependence is about the same, but the curves are seen to be shifted. An additional analysis has shown that the difference between the two branches remains, regardless of the shift ( $-5 \div 0$ years) applied to the $A p_{132}$ variation with respect to the $\delta f o \mathrm{~F} 2{ }_{132}$ one. It seems as if the "efficiency" of geomagnetic disturbances has increased since the middle of the 1960 s as the same $\delta f o F 2_{132}$ values correspond to lower A $p_{132}$ after 1971. 
Table 6. Diurnal variation of the slope $K_{r}$ (in $10^{-4}$ per year) of the residual trend for Slough. The optimal time shift $\Delta t$ (in years) between $\delta f o \mathrm{~F} 2_{132}$ and $A p_{132}$ variations is given as well. Bold face figures show significant trends with a confidence level $95 \%$, normal face figures are trends with a confidence level $90 \%$, italic face figures are trends which are not significant at the $90 \%$ confidence level

\begin{tabular}{c|c|c||c|c|c}
\hline LT & $K_{r}$ & $\Delta t$ & LT & $K_{r}$ & $\Delta t$ \\
\hline 00 & -1.84 & -3 & 12 & -2.76 & -5 \\
01 & -1.68 & -3 & 13 & -2.48 & -4 \\
02 & -1.54 & -3 & 14 & -3.96 & -3 \\
03 & -0.53 & -2 & 15 & -4.27 & -4 \\
04 & +0.12 & -2 & 16 & $-\mathbf{5 . 7 5}$ & -4 \\
05 & +0.45 & -2 & 17 & $-\mathbf{7 . 9 0}$ & -4 \\
06 & +0.04 & -2 & 18 & $-\mathbf{1 0 . 5 0}$ & -4 \\
07 & -0.91 & -3 & 19 & $-\mathbf{8 . 7 6}$ & -4 \\
08 & -2.51 & -3 & 20 & -5.53 & -3 \\
09 & -1.90 & -4 & 21 & -4.75 & -5 \\
10 & -3.39 & -4 & 22 & -2.59 & -4 \\
11 & $-\mathbf{3 . 7 1}$ & -4 & 23 & -1.74 & -3 \\
\hline
\end{tabular}

Table 7. The minimal $S D$ (in $10^{-3}$ ) and corresponding slopes (in $10^{-4}$ per year) of a complementary $K_{c}$ and residual $K_{r}$ trends for Slough (12:00 LT). The start years for the complementary trend to start are shown

\begin{tabular}{c|c|c|c}
\hline Start years & $S D$ & $K_{c}$ & $K_{r}$ \\
\hline 1980 & 4.19 & +2.98 & -1.79 \\
1975 & 3.85 & +3.22 & -1.48 \\
1970 & 3.38 & +3.41 & -1.18 \\
1965 & 3.18 & +3.04 & -1.04 \\
1960 & 2.88 & +3.20 & -0.73 \\
1955 & 2.46 & +3.19 & -0.44 \\
1950 & 2.14 & +3.17 & -0.18 \\
1945 & 2.09 & +3.27 & -0.33 \\
1940 & 1.99 & +3.23 & -0.23 \\
1938 & 2.01 & +3.11 & -0.07 \\
\hline
\end{tabular}

The ambiguity in this dependence can be removed to a great extent by applying a "complementary" linear trend to the $\delta f o \mathrm{~F} 2132$ variation. Table 7 shows the results of such calculations for Slough (12:00 LT) when a complementary trend with the slope Kc was switched on for different start years.

The results of Table 7 show that $S D$ and the slope $K_{r}$ of the residual trend decrease as the start year for the complementary trend shifts towards the beginning of the period in question, with the complementary trend being about the same with the slope $K_{c}$, close to $+3 \times 10^{-4}$ per year. The least $S D$ (the best fitting) is obtained if the complementary trend is applied for the whole period analyzed, starting from the first year, with the latter being important for further discussion. The final variations are shown in Fig. 3 (right-hand boxes). A complementary positive trend with $K_{c}=3.1 \times 10^{-4}$ per year tightens the loops in the $\delta f o \mathrm{~F} 2_{132}$ versus $A p_{132}$ dependence to practically one curve (Fig. 3, right-hand, bottom). The resultant residual trend is close to zero $\left(K_{r}=-0.07 \times 10^{-4}\right.$ per year) in this case. Similar results were obtained for some other stations with the complementary trends depending on station and LT. An example of tightening the loops in the $\delta f o \mathrm{~F} 2{ }_{132}$ versus $A p_{132}$ dependence demonstrates Juliusruh for the 1962-1994 period (Fig. 4).

\section{Discussion}

The proposed approach to the foF 2 trend analysis allows us to remove to a great extent solar and geomagnetic activity effects from $f_{o} \mathrm{~F} 2$ long-term variations and to show that the residual $f_{o} \mathrm{~F} 2$ trends are small both for rising and falling periods of geomagnetic activity (Tables 4 and 5). The residual significant foF2 trend for Slough (12:00 LT), with the longest available period of $f_{o F} 2$ observations, was found to be small with the slope $K_{r}=-2.23 \times 10^{-4}$ per year. Such a small trend gives around $0.1 \mathrm{MHz}$ in the foF2 change over a 55year period for any reasonable mean foF2 value accepted. Therefore, such trends have no practical importance. But from a physical point of view, the obtained result is interesting, telling us that practically all observed foF2 long-term variations may be attributed to the variations in solar and geomagnetic activity, i.e. they are of a natural origin. Although this result was obtained using conventional indices, $R_{12}$ and $A p$, they should be converted to $R_{12}^{\alpha}$ and $A p_{132}$, to be used in the trend analysis. This is due to the fact that initial $R_{12}$ and monthly $A p$ cannot properly present solar and geomagnetic activity effects in the $f o \mathrm{~F} 2$ long-term variations and more efficient indices are required. There are some related problems. The first one concerns the procedure of the solar activity effect removal. The commonly accepted approach is based on the foF2 regression (linear dependence) with sunspot number $R_{12}$. This came from empirical modelling (for instance, IRI-90), where quite a different problem was solved. The goal of monthly median ionosphere empirical modelling is to find the best approximation for the observed monthly median $f_{o} \mathrm{~F} 2, M(3000) \mathrm{F} 2, f_{o} \mathrm{~F} 1$, or $f_{o} \mathrm{E}$ solar cycle variations using any index of solar activity. A linear or nonlinear relationship with direct solar indices $\left(R_{12}, F_{10.7}\right)$ or ionospheric indices ( $T, I G, M F 2$ ) is used to solve this problem (e.g. Mikhailov and Mikhailov, 1999 and references therein). Monthly foF2 medians include both solar and geomagnetic activity effects and the empirical relationship with $R_{12}$ is no more than a successful approximation, having practically nothing to do with the F2-layer formation mechanisms. Therefore, using the regression of foF 2 with $R_{12}$ we attribute to $R_{12}$ both effects in the observed foF 2 variations. Whether it is possible to describe "pure" foF 2 solar activity variations using the $R_{12}$ index and how such a dependence looks like is a question of special consideration. Anyway, it is clear that such a "pure" dependence cannot just be a linear regression of $f_{o} \mathrm{~F} 2$ with $R_{12}$, which only presents the first term of an expansion in a power series of $R_{12}$. 
As an example, this can be shown for the mid-latitude summer daytime F2-layer, when vertical plasma drift is close to zero due to small thermospheric winds. For such geophysical conditions we can use the well-known expressions by Rishbeth and Barron (1960)

$N_{m} F 2=0.75 \times q_{m} / \beta_{m}, \quad \beta_{m} \times H^{2} / D_{m}=0.6$,

where ion production rate, $q_{m}$, linear loss coefficient, $\beta_{m}$, and ambipolar diffusion coefficient, $D_{m}$, are given at the F2layer maximum, with $H$ being the atomic oxygen neutral scale height. These two expressions may be combined and re-written for a fixed height $h_{1}$, say $300 \mathrm{~km}$ (Mikhailov et al., 1995), to give

$N_{m} F 2 \propto \frac{I_{o}[\mathrm{O}]_{1}^{4 / 3}}{T_{n}^{5 / 6}\left[\mathrm{~N}_{2}\right]_{1}^{2 / 3}}$,

where $I_{o}$ - solar $E U V$ flux, [O] and $\left[\mathrm{N}_{2}\right]$ - atomic oxygen and molecular nitrogen concentration, $T_{n}$ - neutral temperature. According to the Nusinov $(1984,1992)$ model total solar $E U V$ flux is $I_{0} \propto F_{10.7}^{2 / 3}$. The ratio of thermospheric parameters in Eq. (5) may be estimated using the MSIS-86 thermospheric model (Hedin, 1987). This ratio may be shown to be proportional to $F_{10.7}^{4}$ at $300 \mathrm{~km}$ height. Therefore,

$f o F 2 \propto \sqrt{N_{m} F 2} \propto F_{10.7}^{7 / 3}$.

Annual mean $F_{10.7}$ and $R_{12}$ indices are known to be highly correlated (the correlation coefficient is 0.991 , and is significant at the $99 \%$ confidence level). Then we obtain $f o \mathrm{~F} 2 \propto$ $R_{12}^{2.33}$. According to our calculations for Slough (as an example), the summer daytime (12:00 LT) $\alpha$ values are the following: May (2.43), Jun (2.61), Jul (2.78), Aug (1.85), which are close to the above made estimate. Therefore, the "pure" $f o \mathrm{~F} 2$ dependence on $R_{12}$ may differ essentially from just the linear law usually used in the $f o \mathrm{~F} 2$ long-term trend analysis. It should be stressed once again that the regression (1) is not a "model" in the usual sense of the word, since it is accepted in all earlier approaches. This regression removes the solar activity part from the observed $f_{o} \mathrm{~F} 2$ variations, rather than drawing the best curve over the observed points.

The other problem concerns the removal of geomagnetic activity effects from the $f o \mathrm{~F} 2$ variations. The use of monthly or even annual mean $A p$ indices is not efficient as our analysis has shown. Indeed, an inclusion of the monthly $A p$ index to the regression does not remove the geomagnetic activity effects, but only contaminates (due to low correlation with monthly $f o \mathrm{~F} 2$ ) the analyzed material without changing, in principle, the results obtained (Mikhailov and Marin, 2000). As it was mentioned earlier, the usual monthly foF2 medians bear F2-layer storm effects (geomagnetic activity effects) which, however, cannot be removed using conventional monthly $A p$ indices. This is not surprising, since the global $A p$ index cannot, in principle, take into account the whole complexity of the F2-layer storm effects with positive and negative phases depending on season, UT and LT of storm onset, storm magnitude, etc. Therefore, an interpretation of the F2-layer parameter long-term trends (based on previous methods) should consider the geomagnetic effects as an inalienable part of the trends revealed, and this can be done based on the contemporary understanding of the F2layer storm mechanisms (Mikhailov and Marin, 2000, 2001).

A fruitful idea has been proposed by Deminov et al. (2000), who used quiet time $f o \mathrm{~F} 2$ median ( $Q$-median) values to analyze the $f o \mathrm{~F} 2$ long-term trend for Slough. Specially selected quiet time periods were used to produce such monthly $Q$-medians, which are free from short-term (monthly) variations of geomagnetic activity. We have used a simpler approach to obtain $f o \mathrm{~F} 2 Q$-medians, which are also free from short-term geomagnetic activity effects (as our analysis has shown), but long-term geomagnetic activity variations are still present in such $f o \mathrm{~F} 2 Q$-medians. This is clearly seen in Fig. 2, where the $\delta f o \mathrm{~F} 2$ variation closely follows the longterm $A p_{132}$ changes with $\mathrm{a} \approx 4$-year time shift.

An essential point of the proposed method is the 11-year running mean smoothing of $\delta f o \mathrm{~F} 2$ and $A p$ values. The use of 11-year smoothing conquers quasi-biannual $\delta f o \mathrm{~F} 2$ oscillations (Fig. 1), which are not removed by any regression with monthly or annual mean $A p$, due to low correlation coefficients. This is a principle point which usually is not taken into account during the trend analysis. As far as we know, only Ulich and Turunen (1997) and Deminov et al. (2000) used correspondingly 11-year and 5-year smoothing in their analyzes. Our consideration has shown that only the use of 11-year running mean $\delta f o \mathrm{~F} 2$ and $A p$ smoothing, along with a polynomial approximation of these variations (which works as an additional smoothing), allows one to bring up to the $0.90-0.95$ correlation coefficient level (Table 1 ). Only with such high correlation coefficients (which are significant at the $95-99 \%$ confidence level) it is possible to draw a conclusion that observed $f o \mathrm{~F} 2$ long-term variations can be presented mainly by solar and geomagnetic activity variations.

The 11-year smoothing of $\delta f o \mathrm{~F} 2$ values enable us to use all years with observations, rather than only years around solar minimum $(\mathrm{m})$ or solar minima and maxima $(\mathrm{m}+\mathrm{M})$. The latter was the crucial point of our previous method (Danilov and Mikhailov, 1999; Mikhailov and Marin, 2000), which allowed us to avoid the hysteresis effect in $f o \mathrm{~F} 2$ solar cycle variations. The effect is known to take place at the rising and falling parts of a solar cycle and is due to peculiarities in solar $E U V$ flux and geomagnetic activity variations in the course of a solar cycle (Mikhailov and Mikhailov, 1995).

An interesting result is a $-3 \pm 1$-year time shift between $A p_{132}$ and $\delta f o \mathrm{~F}_{132}$ variations (Table 3 ), which provides the maximal correlation coefficient (Table 1). The results of the calculations show that this time shift varies slightly from station to station (for one and the same LT) and depends on LT at a given station (Table 6). An analysis of this problem is out of scope for this paper and now it is not clear what the mechanism of such a 3-4 year delay is in the thermosphere reaction to the long-term changes in geomagnetic activity. Such a large time delay implies that the whole Earth's atmosphere is involved with the processes provoked by geomagnetic activity. Changes in the global atmospheric circulation 


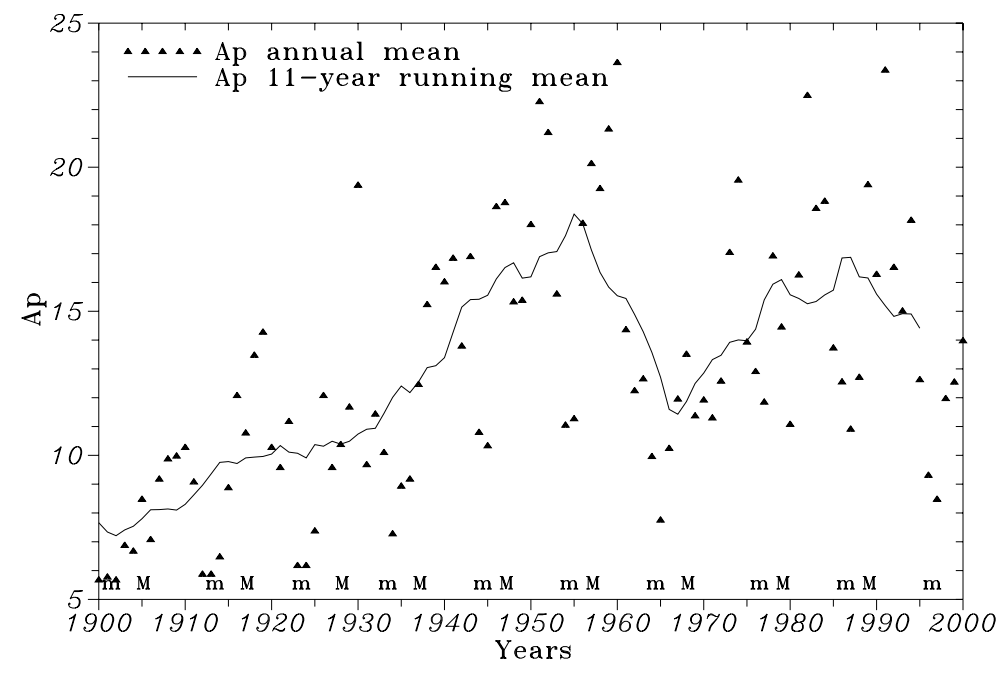

Fig. 5. Annual mean and 11-year running mean $A p$ index variations during the 20th century. Annual mean $A p$ indices prior to 1932 were reconstructed from $a a$ indices available since 1868 . Symbols (m) and (M) refer to years of solar cycle minimum and maximum. and related variations in the thermospheric neutral composition and temperature are the most probable mechanisms.

Although the proposed approach essentially deletes solar and geomagnetic activity effects and gives small and insignificant residual $f o \mathrm{~F} 2$ trend for the rising period of geomagnetic activity (Table 4), most of these trends are negative. Slough (12:00 LT) also demonstrates negative and significant residual trend calculated over the 55-year period which include both rising and falling periods in geomagnetic activity (Fig. 3, left-hand box).The same result was obtained on diurnal variations for Slough (Table 6). Therefore, this result can hardly be coincidental. Negative $f o F 2$ trends may be considered as a manifestation of the geomagnetic control which is not completely removed by the proposed method. Indeed, there is a very long-term increase in geomagnetic activity (e.g. Clilverd et al., 1998) which requires more smoother than $A p_{132}$ indices for its description. This long-term increase takes place even for the analyzed period (Fig. 2, top), where a positive ( $K=0.02$ per year) trend is seen in the observed $A p_{132}$ variation. Figure 2 (top) is only a fragment of the general picture showing the increase in geomagnetic activity in the course of the 20th century (Fig. 5). This is a very delicate question which requires special consideration and is not discussed here.

An inclusion of a complementary linear $\delta f o \mathrm{~F} 2$ trend to our analysis restores the unambiguity in the $\delta f o \mathrm{~F} 2_{132}$ versus $A p_{132}$ dependence (Figs. 3 and 4 ) and practically results in a zero residual trend. Let us consider the sense of this complementary trend. The loop in the $\delta f o \mathrm{~F} 2{ }_{132}$ versus $A p_{132}$ dependence (Figs. 3 and 4), in principle, may be related to some changes in the $A p$ index determination after the middle of the 1960s (new stations, a modified method, etc.). The difference between the two branches is not large (10-15\%), but it is clearly seen in Figs. 3 and 4. On the other hand, Fig. 4 (top) shows that we have a new branch after 1990, shifted in the same direction and this can hardly be related to any changes in the method of the $A p$ index determination. Therefore, we should accept that observed $\delta f o \mathrm{~F} 2{ }_{132}$ values include an addi- tional negative long-term trend which is not described by $R_{12}^{\alpha}$ and $A p_{132}$ variations and the complementary trend just compensates it. An intriguing explanation of the complementary trend could be related to the anthropogenic activity, such as, for instance, the increasing rate of rocket and satellite launching, which leads to the thermosphere pollution (Kozlov and Smirnova, 1999; Adushkin et al., 2000). Indeed, switching on a complementary trend since 1960 (as the beginning of the cosmic era) improves to some extent the picture with the loops in Figs. 3 and 4, but the best results (the least $S D$ ) are obtained if the trend is switched on from the first year (1938) of the period analyzed (Table 7). It is impossible to link this result with the anthropogenic space pollution. Therefore, the only plausible explanation (as it is seen from now) of the complementary trend is a compensation of a negative trend initially presented in the observed $\delta f o \mathrm{~F} 2{ }_{132}$ values. This negative trend presumably has the same F2-layer storm nature as discussed by Mikhailov and Marin (2001) and is due to the earlier discussed very long-term increase in geomagnetic activity in the 20th century.

\section{Conclusions}

1. A new method to extract $f o \mathrm{~F} 2$ long-term trends, which are free to a great extent from solar and geomagnetic activity effects, has been proposed. This is achieved by using:

(a) a foF2 regression with $R_{132}^{\alpha}$ (where $\alpha$ is a fitting parameter) to remove the solar activity part from the $f \circ \mathrm{F} 2$ long-term variations;

(b) relative rather than absolute $\delta f o \mathrm{~F} 2$ deviations to find $\delta f o 2_{132}$ (11-year running mean values);

(c) a regression with $A p_{132}$ (11-year running mean $A p$ values) to remove the geomagnetic activity effects from the $f o \mathrm{~F} 2$ long-term variations. Both $\delta f o \mathrm{~F} 2{ }_{132}$ and $A p_{132}$ variations are to be further smoothed, 
to provide the best correlation coefficients. Neither monthly nor annual mean $\delta f o \mathrm{~F} 2$ values provide a high enough correlation with $A p$ indices and cannot be recommended for the $f o \mathrm{~F} 2$ trend analysis;

(d) $f o \mathrm{~F} 2$ quiet time ( $Q$-medians) rather than usual monthly medians;

(e) all available $\delta f o \mathrm{~F} 2$ observations rather than (m) or $(\mathrm{m}+\mathrm{M})$ year selections used in the previous version of our method;

(f) a $-3 \pm 1$-year time shift between $A p_{132}$ and $\delta f o \mathrm{~F} 2{ }_{132}$ variations, to obtain the best correlation (the least $S D$ ). This time shift may be due to a large delay in the thermosphere reaction to the long-term changes in geomagnetic activity, with the physical mechanism of such an influence being unclear now.

2. The $f o \mathrm{~F} 2$ trends calculated for rising and falling phases of the long-term geomagnetic activity variation show neither latitudinal dependence nor any dependence on the phase being small and insignificant. The existence of such dependencies for the trend magnitude was the basic point of the geomagnetic control concept by Mikhailov and Marin $(2000,2001)$.

3. The residual trend for Slough, calculated over the 55year period, is small $\left(K_{r}=-2.2 \times 10^{-4}\right.$ per year $)$ and significant. Such small $f o F 2$ trends have no practical importance. On the other hand, negative (although primarily insignificant), residual trends that are calculated over 10 ionosonde stations for a shorter period (31 years) may be considered as a manifestation of a very long-term geomagnetic activity increase, which did take place in the 20th century (Clilverd et al., 1998). But this effect cannot be removed even by using very smoothed indices, such as $A p_{132}$.

4. The main conclusion is that all revealed foF2 long-term variations (trends) may be attributed to the long-term solar and geomagnetic activity variations, i.e. they are of a natural origin. There is no indication of any manmade foF 2 trends.

Acknowledgement. This work was in part supported by the Russian foundation for Fundamental Research under Grant 00-05-64189.

Topical Editor M. Lester thanks M. Jarvis and P. Wilkinson for their help in evaluating this paper.

\section{References}

Adushkin, V. V., Kozlov, S. I., and Petrov A. V.: Ecological problems and risks of the rocket and space technique impact on the environment, Moscow, Ankil, 638, 2000 (in Russian).

Bremer, J.: Ionospheric trends in mid-latitudes as a possible indicator of the atmospheric greenhouse effect, J. Atmos. Terr. Phys., 54, 1505-1511, 1992.

Bremer, J.: Trends in the ionospheric E- and F-regions over Europe, Ann. Geophysicae., 16, 986-996, 1998.
Clilverd, M. A., Clark, T. D. G., Clarke, E., and Rishbeth, H.: Increased magnetic storm activity from 1868 to 1995, J. Atmos. Solar-Terr. Phys., 60, 1047-1056, 1998.

Danilov, A. D.: Long-term changes of the mesosphere and lower thermosphere temperature and composition, Adv. Space Res., 20, 2137-2147, 1997.

Danilov, A. D.: Review of long-term trends in the upper mesosphere, thermosphere and ionosphere, Adv. Space Res., 22, 907915, 1998.

Danilov, A. D. and Mikhailov, A. V.: Spatial and seasonal variations of the $f o$ F2 long-term trends, Ann. Geophysicae., 17, 1239-1243, 1999.

Danilov, A. D. and Mikhailov, A. V.: F2-layer parameters longterm trends at the Argentine Islands and Port Stanley stations, Ann. Geophysicae, 19, 341-349, 2001.

Deminov, M. G., Garbatsevich, A. V., and Deminov R. G.: Climatic changes of the ionospheric F2-layer, Doklady RAN, 372, 383385, (in Russian), 2000.

Foppiano, A. J., Cid, L, and Jara, V.: Ionospheric long-term trends for South American mid-latitudes, J. Atmos. Solar-Terr. Phys., 61, 717-723, 1999.

Givishvili, G. V. and Leshchenko, L. N.: Possible proofs of presence of technogenic impact on the midlatitude ionosphere, Doklady RAN, 334, 213-214, (in Russian), 1994.

Givishvili, G. V. and Leshchenko, L. N.: Dynamics of the climatic trends in the midlatitude ionospheric E-region, Geomag. i Aeronom., 35, 166-173, (in Russian), 1995.

Givishvili, G. V., Leshchenko, L. N., Shmeleva, O. P., and Ivanidze T. G.: Climatic trends of the mid-latitude upper atmosphere and ionosphere, J. Atmos. Terr. Phys., 57, 871-874, 1995.

Hedin, A. E.: MSIS-86 thermospheric model, J. Geophys. Res., 92, 4649-4662, 1987.

Jarvis, M. J., Jenkins, B., and Rodgers G. A.: Southern hemisphere observations of a long-term decrease in F-region altitude and thermospheric wind providing possible evidence for global thermospheric cooling, J. Geophys. Res., 103, 20 774-20 787, 1998.

Ivanov-Kholodny, G. S.: Solar $E U V$ quasi-biennial variations, Phys. Chem. Earth (C), 25, 433-435, 2000.

Ivanov-Kholodny, G. S. and Chertoprud, V. Ye.: Analysis of extrema of quasi-biennial variations of solar activity, Astron. and Astrophys. Trans., 3, 81-85, 1992.

Kozlov, S. I. and Smirnova, N. V.: Estimation of the influence of helio-geophysical conditions on characteristics of ionospheric disturbances produced by rocket launches, Cosmic Res., 37, 507-514, (in Russian), 1999.

Marin, D., Mikhailov, A. V., de la Morena, B. A., and Herraiz, M.: Long-term $h m \mathrm{~F} 2$ trends in the Eurasian longitudinal sector from the ground-based ionosonde observations, Ann. Geophysicae, 19, 761-772, 2001.

Mikhailov, A. V. and Marin, D.: Geomagnetic control of the $f_{o} \mathrm{~F} 2$ long-term trends, Ann. Geophysicae, 18, 653-665, 2000.

Mikhailov, A. V. and Marin, D.: An interpretation of the $f o \mathrm{~F} 2$ and $h m \mathrm{~F} 2$ long-term trends in the framework of the geomagnetic control concept, Ann. Geophysicae, 19, 733-748, 2001.

Mikhailov, A. V. and Mikhailov, V. V.: Solar cycle variations of annual mean noon $f o F 2$, Adv. Space Res., 15, 79-82, 1995.

Mikhailov, A. V. and Mikhailov, V. V.: Indices for monthly median $f o \mathrm{~F} 2$ and $\mathrm{M}(3000) \mathrm{F} 2$ modeling and long-term prediction: Ionospheric index MF2, Inter. J. Geomag. and Aeronom., 1, 141-151, 1999.

Mikhailov, A. V., Skoblin, M. G, and Förster, M.: Daytime F2layer positive storm effect at middle and lower latitudes, Ann. Geophysicae, 13, 532-540, 1995. 
Muhtarov, P. and Kutiev, I.: Geomagnetically correlated statistical model (GCSM) for short-term prediction of ionospheric parameters, Proc. of the 2nd COST 251 Workshop, 30-31 March 1998 Side, Turkey, 246-251, 1998.

Nusinov, A. A.: Dependence of intensity in lines of solar short-wave radiation on activity level, Geomag. i Aeronom., 24, 529-536, (in Russian), 1984.

Nusinov, A. A.: Models for prediction of $E U V$ and $X$-ray solar radiation based on $10.7 \mathrm{~cm}$ radio emission, in: Proc. Workshop on Solar Electromagnetic Radiation for Solar Cycle 22, (Ed) Donnely, R. F., Boulder, Co., July 1992, NOAA ERL. Boulder, Co., USA, 354-359, 1992.

Pollard, J. H.: A handbook of numerical and statistical techniques, Camb.Univ. Press, 1977.

Press, W. H., Teukolsky, S. A., Vetterling, W. T., and Flannery, P.: Numerical recipes in Fortran 77, Cambridge University Press, Cambridge, UK, 1992.

Rishbeth, H.: A greenhouse effect in the ionosphere?, Planet. Space Sci., 38, 945-948, 1990.

Rishbeth, H.: Long-term changes in the ionosphere, Adv. Space Res., 20, 2149-2155, 1997.
Rishbeth, H. and Barron, D. W.: Equilibrium electron distributions in the ionospheric F2-layer, J. Atmos. Terr. Phys., 18, 234-252, 1960.

Rishbeth, H. and Roble, R. G.: Cooling of the upper atmosphere by enhanced greenhouse gases - Modelling of thermospheric and ionospheric effects, Planet. Space Sci., 40, 1011-1026, 1992.

Sharma, S. S., Chandra, H., and Vyas, G. D.: Long-term ionospheric trends over Ahmedabad, Geophys. Res. Lett., 26, 433436, 1999.

Ulich, T. and Turunen, E.: Evidence for long-term cooling of the upper atmosphere in ionospheric data, Geophys. Res. Lett., 24, 1103-1106, 1997.

Upadhyay, H. O. and Mahajan, K. K.: Atmospheric greenhouse effect and ionospheric trends, Geophys. Res. Lett., 25, 3375-3378, 1998.

Zevakina, R. A. and Kiseleva, M. V.: F2-layer parameter variations during positive disturbances related to phenomena in the magnetosphere and interplanetary medium, In: The diagnostics and modelling of the ionospheric disturbances, Nauka, Moscow, 151-167, (in Russian), 1978. 